\title{
Comparison of bupivacaine, xylazine and buprenorphine with ketamine combination for spinal analgesia in buffalo calves
}

\author{
Rekha Pathak, K. Pratap, Amarpal, P Kinjavdekar, H.P. Aithal, Pankaj \\ Indian Veterinary Research Institute, \\ Izatnagar, Bareilly-243 122, UP, India \\ Corresponding author: Rekha Pathak, email: rekhasurgery@gmail.com \\ Received: 13-07-2012, Accepted: 30-07-2012 \\ doi: $10.5455 /$ vetworld.2012.754-761
}

\begin{abstract}
Aim: The study was undertaken to compare the clinical efficacy of lumbosacral spinal analgesia produced using bupivacaine, xylazine and buprenorphine with ketamine combination in buffalo calves

Materials and Methods: 36 male buffalo calves of seven to eight months of age and weighing 60 to $75 \mathrm{~kg}$ were used to evaluate the efficacy and safety of lumbosacral spinal analgesia produced by bupivacaine $0.25 \mathrm{mg} / \mathrm{kg}$, xylazine $0.05 \mathrm{mg} / \mathrm{kg}$ and buprenorphine $20 \mu \mathrm{g} / \mathrm{kg}$ in combination with ketamine $2.5 \mathrm{mg} / \mathrm{kg}$ and divided into groups A, B and C, respectively with 12 animals in each group.

Results: The onset of analgesia in animals of group A (bupivacaine + ketamine) was $3.0 \pm 0.3$ min, group B (xylazine + ketamine) was recorded as $2.6 \pm 0.4 \mathrm{~min}$ and group $\mathrm{C}$ (buprenorphine + ketamine) $4.0 \pm 0.4 \mathrm{~min}$. Ketamine-bupivacaine in animals of group A produced complete analgesia of almost all the dermatomes for varying lengths of time. So also the group $\mathrm{B}$ except that it produced only moderate analgesia of thorax, abdomen and flank. Animals of group C produced only mild analgesia of thorax, abdomen and flank and moderate analgesia of digits, perineum, inguinal, himd limbs and tail region. The longest (>180 min.) duration of complete analgesia was recorded in animals of group A. The heart rate and respiration rate significantly decreased in group A and B than group C, so also the rectal temperature. Sedation recorded was maximum in group B fallowed by group A and least sedation scores were given by group C animals. Similiarly the scores of motor incordination was higher in group B and group A than group $\mathrm{C}$.

Conclusion: It was concluded that the combinations viz. Bupivacaine+ Ketamine and Xylazine + ketamine when given intraspinally at the lumbosacral space have similar analgesic potency on spinal administration in buffaloes. The synergism is more pronounced in xylazine-ketamine combination, whereas Buprenorphine +ketamine combination in the above said dose is a poor analgesic agent when used intraspinally at the lumbosacral space in buffalo calves.

Key words: buffalo calves, bupivacaine, buprenorphine, ketamine, lumbosacral, spinal, xylazine
\end{abstract}

To cite this article: Pathak R, Pratap K, Amarpal, Kinjavdekar P, Aitha HP, Pankaj (2012), Comparison of bupivacaine, xylazine and buprenorphine with ketamine combination for spinal analgesia in buffalo calves, Vet World, 5(12): 754-761, doi: 10.5455/vetworld.754-761

\section{Introduction}

Since general anaesthetics affect cardiovascular system in animals, general anesthesia should thus be avoided in patients with increased blood urea nitrogen level [1]. Local and regional anesthesia would be a better choice in such patients. In this study three drugs (long acting nature) of different classes were selected viz; long acting local anesthetic, alpha-2- agonist and an opioid: they were respectively combined with ketamine to attain synergistic effect.

Epidural analgesia produced by bupivacaine or xylazine has been reported to effectively reduce post operative pain in goats. [2,3] and human beings [4]. Bupivacaine, has been used in for preemptive, and post-traumatic analgesia and for laparotomy in goats [3].

Xylazine, an alpha -2 agonist, has been used to induce sacrococcygeal/lumbosacral spinal analgesia in different species of animals and produces a longer duration of regional analgesia $[5,6]$. Epidural xylazine produced a significantly greater duration of analgesia, in adult Holstein cows than did epidural lidocaine. The incidence of ataxia associated with the use of xylazine would also be expected to be less than lidocaine. Further, when xylazine, given epidurally, produced greater perineal analgesia than did xylazine given intramuscularly [7].

It has been shown in a number of species that opioids produce selective caudal epidural analgesia, 
Comparison of bupivacaine, xylazine and buprenorphine with ketamine combination in buffalo calves

Table-1. Scores scale (0-3) of analgesia, motor incordination and sedation.

\begin{tabular}{|c|c|c|c|}
\hline Score & Analgesia & Ataxia/ Motor incoordination & Sedation \\
\hline 0 & No analgesia strong avoidance response to the pinpricks & Animal walking without staggering & Animal standing alert \\
\hline 1 & Mild analgesia weak avoidance response to the pinpricks & $\begin{array}{l}\text { Animal able to stand and walk with little } \\
\text { in-coordination }\end{array}$ & $\begin{array}{l}\text { Animal appeared tired } \\
\text { with slight ptosis of eyelids }\end{array}$ \\
\hline 3 & $\begin{array}{l}\text { Complete analgesia no avoidance response to the } \\
\text { pinpricks }\end{array}$ & $\begin{array}{l}\text { Animal unable to stand and became } \\
\text { recumbent }\end{array}$ & $\begin{array}{l}\text { Animal standing with wide } \\
\text { stance and extreme lowering } \\
\text { of head }\end{array}$ \\
\hline
\end{tabular}

by activating specific spinal receptors. Epidural opioids have been used since long in human beings for relieving of post-operative pain. Buprenorphine is a partial mu opioid agonist and a strong kappa antagonist with long duration of action. It has a very wide margin of safety [8]. NMDA receptor antagonists appears to inhibit the neural plasticity underlying some forms opiate tolerance, sensitization and physical dependence, suggesting that NMDA receptors are involved in the develpment of these drugs induced changes in behaviour [9].

Ketamine has been used to enhance the depth of epidural analgesia produced by xylazine in animals and that produced by local anaesthesia in human beings. Further, ketamine has been reported to have least cardiopulmonary effects when used epidurally. The present study therefore, was designed to evaluate and compare the utility of ketamine combination drugs viz. Bupivacaine-ketamine, Xylazine- Ketamine and Buprenorphine-Ketamine to produce spinal analgesia.

\section{Materials and Methods}

36 non- descript male buffalo calves of 7-8 months of age , weighing from $60-75 \mathrm{~kg}$ were equally divided into 3 groups of 12 animals each, designated as groups $\mathrm{A}, \mathrm{B}$ and $\mathrm{C}$. The animals were dewormed and vaccinated against important infectious and contagious diseases HS and FMDV and were maintained under uniform managemental conditions. The animals were kept off feed for 24 hours and water was withheld 12 hours prior to the start of the experiment. The Animal Ethics Committee of the Indian Veterinary Research Institute, Izatnagar, India, approved the study. The animals were restrained in standing position with cotton rope halters in a cattle crush. The lumbosacral space was palpated and the area of injection was clipped, shaved and painted with povidone iodine for aseptic spinal injection. An initial weal was produced with $2 \%$ lignocaine hydrochloride using a fine needle at the center of lumbosacral space. In group A bupivacaine $0.25 \mathrm{mg} / \mathrm{kg}$, in group $\mathrm{B}$, xylazine 0.05 $\mathrm{mg} / \mathrm{kg}$, in group C buprenorphine $20 \mu \mathrm{g} / \mathrm{kg}$ was administered intraspinally respectively in combination with ketamine $2.5 \mathrm{mg} / \mathrm{kg}$ at the lumbosacral space using a 18 gauge, $7.5 \mathrm{~cm}$ spinal needle under aseptic conditions. Total quantity of injectable solution was made up to $6 \mathrm{ml}$ by addition of normal saline solution in each group.

Observations: The animals were observed for clinical and physiological parameters. Onset of analgesia was determined by recording the response to skin pinpricks, using a $24-S W G$ made in the perineal region on either side of midline about $4-5$ centimeters below the anus after wiping off with cotton swab soaked in spirit. A strong avoidance response manifested by kicking, quick shifting of weight on the hind limbs, rapid tail movements or turning and shaking of the head was considered as the normal response of the animal towards the stimulus. The time from the spinal injection to the time of diminished response to pinprick stimulus was recorded as the time of onset of analgesia. The intensity of analgesia at the tail dorsal aspect, perineum both sides of the midline, inguinal region, the upper parts of the hind limbs medial and lateral aspects of the thighs, the digits just distal to fetlock, flank three sites on the lateral abdominal wall; caudal, middle and cranial, ventral abdomen three sites; caudal, middle and cranial and the thorax at the level of each rib starting from the last rib was determined by recording the response of the animals to pinpricks at these sites. The depth of analgesia at the different sites was graded by observing the response of the animal to the pinpricks on a 0 to 3 scale using a scoring system as given in Table 1 below. Depth of analgesia was recorded at 0,5 , $10,15,20,30,45,60,75,90,105,120,130,150$ and 180 minutes after injection of drugs.

Ataxia and sedation: Ataxia and sedation was graded on a 0 to 3 scale using a scoring system as given in Table 1 .

Duration of analgesia: The time from the loss of sensation at the perineum to the time of return of full sensation at all the sites was considered as the duration of analgesia. 

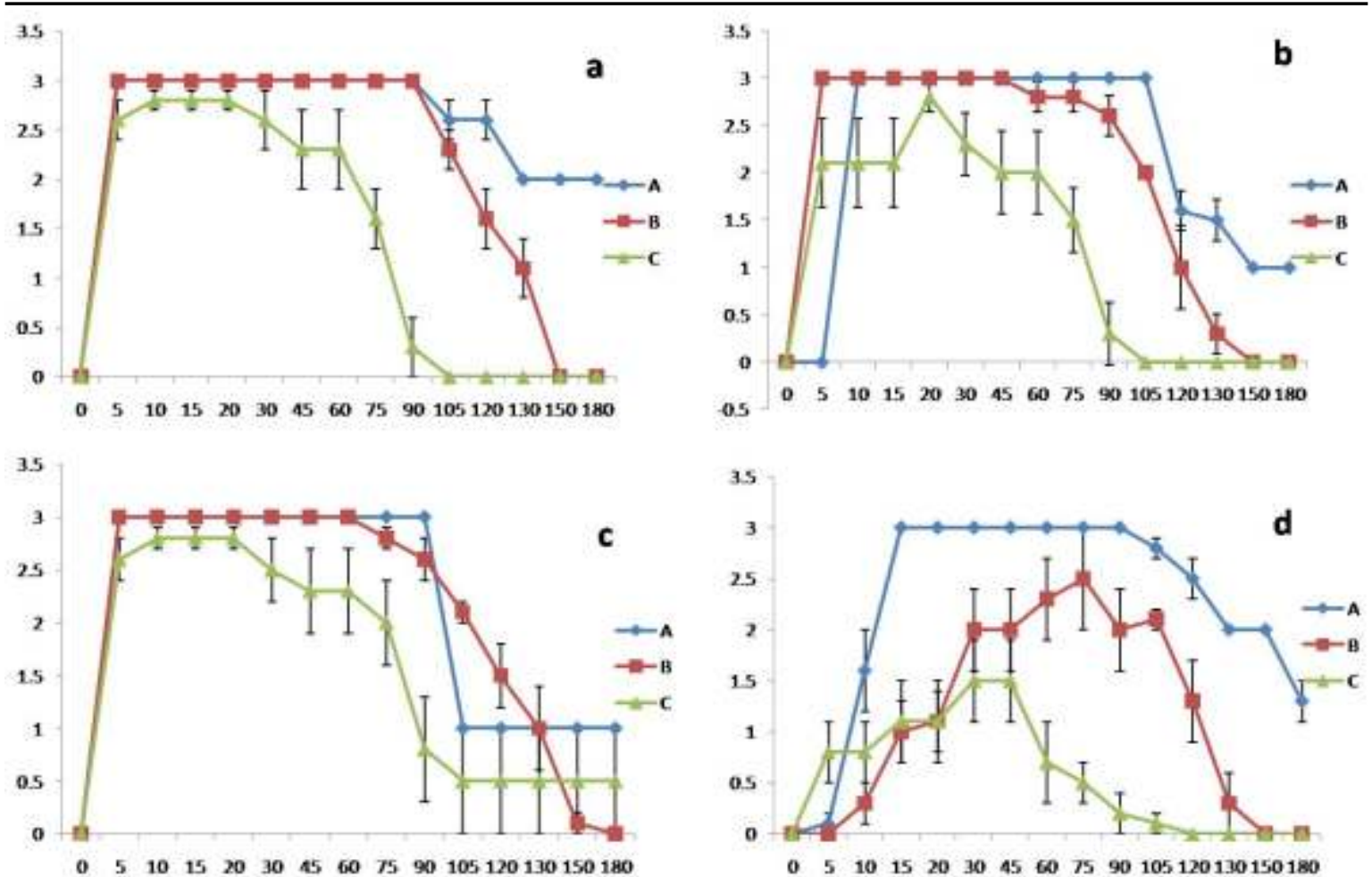

Figure-1. Scores of analgesia at (a) Perineum (b) Inguinal region (c) Tail region (d) Flank, after spinal admistration of the drugs (A; bupivacaine $B$; bupivacaine+ketamine)

Physiological Parameter: Heart rate, Respiration rate and rectal temperature were also recorded on the above intervals.

Statistical analysis: Analysis of variance and Duncan's multiple range test were used to compare the data of parametric observations at different intervals between the groups. Paired t-test with Bonferroni correction was used for comparison of mean $\pm \mathrm{SE}$ at different time intervals with the base values of the respective treatments as per the standard procedures of Snedecor GW \& Cochran WG 1967. Kruskal - Wallis's one way test was used to compare the means among the groups of non-parametric observations. The values were considered as significant at $\mathrm{P}<0.05$ and $\mathrm{P}<0.01$.

\section{Results}

The onset of analgesia in animals of group A (bupivacaine + ketamine) was $3.0 \pm 0.3 \mathrm{~min}$, group B (xylazine + ketamine) was recorded as $2.6 \pm 0.4 \mathrm{~min}$ and group C (buprenorphine + ketamine) 4.0 $\pm 0.4 \mathrm{~min}$. The total duration of analgesia in group $\mathrm{A}$ and $\mathrm{B}$ was more than $180 \mathrm{~min}$.

Summary of depth and extent of analgesia:
Ketamine-bupivacaine in animals of group A produced complete analgesia of digits, perineum, inguinal region, abdomen, hind limbs, tail and flank region and moderate analgesia of thorax for varing lengths of time (Fig 1 and Fig 2). Ketamine-xylazine in animals of group B produced moderate analgesia of thorax, abdomen and flank and complete analgesia of digits, perineum, inguinal region, hind limbs and tail. Ketamine-buprenorphine in animals of group $\mathrm{C}$ produced only mild analgesia of thorax, abdomen and flank and a maximum of moderate analgesia of digits, perineum, inguinal region, hind limbs and tail region. Analgesia in group A and B didn't differ significantly $(\mathrm{P}>0.05)$ from each other but analgesia weaned off in group B at $150 \mathrm{~min}$ and continued to persist at moderate level in group $\mathrm{A}$, throughout the observation period. The longest (>180 min.) duration of complete analgesia was recorded in animals of group A.

Sedation recorded: Comparison between A, B and C groups shows that, Group A animals showed significantly higher $(\mathrm{P}<0.05)$ sedation from 60 to 180 min post injection, as compared to group $\mathrm{C}$, similarly group B (ketamine-xylazine) animals, after a mild phase of sedation showed significantly higher $(\mathrm{P}<$ 

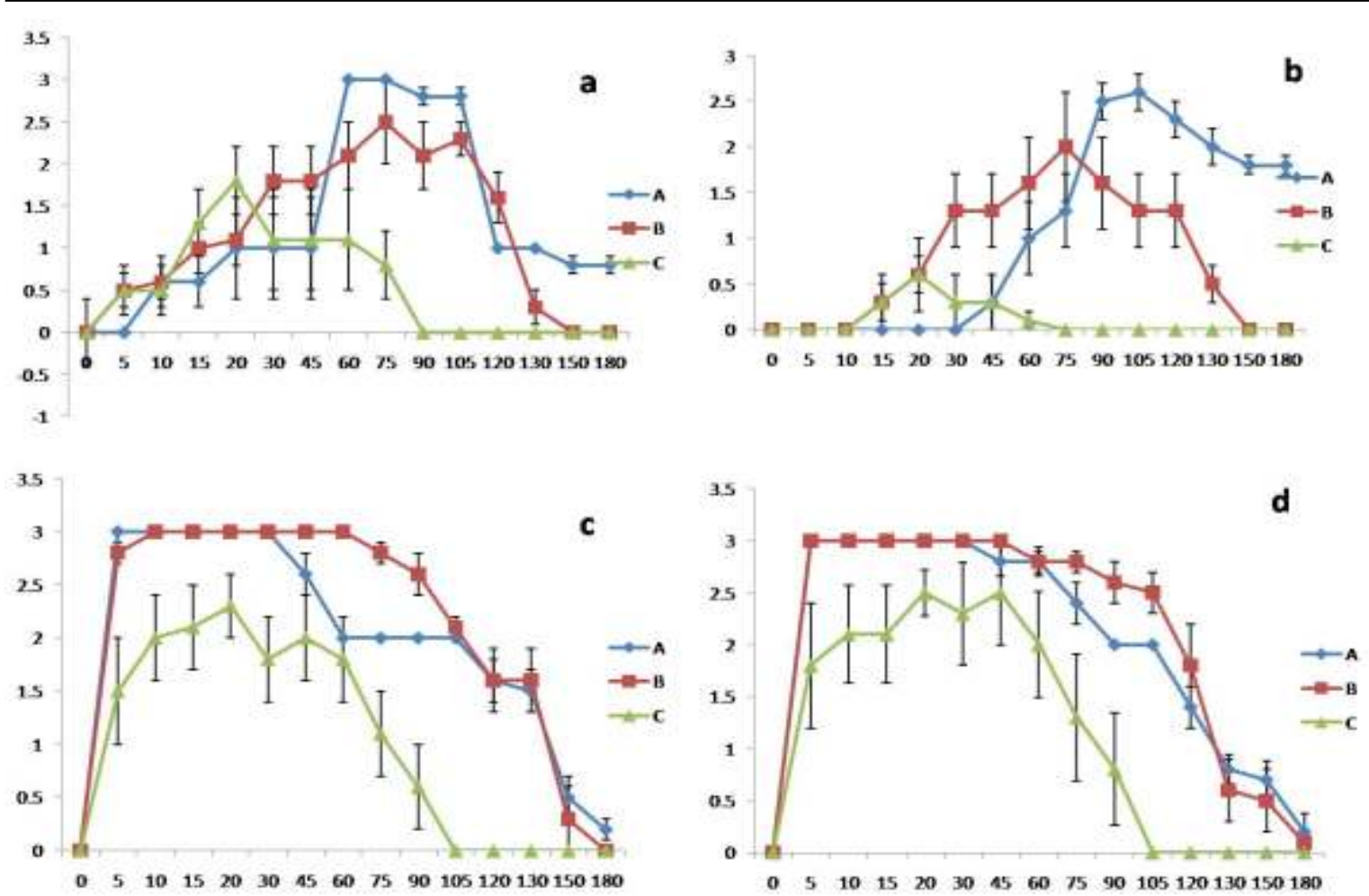

Figure-2. Scores of analgesia at (a) Abdomen (b) thoracic region (c) hind limb and (d) digits after spinal admistration of the drugs ( $A$; bupivacaine $B$; bupivacaine+ketamine)

0.05) sedation degree as compared to group C (Fig 3a).

Motor incoordination: Comparison among A, B and $\mathrm{C}$ groups revealed that motor incoordination was significantly $(\mathrm{P}<0.05)$ high in group $\mathrm{A}$ and group $\mathrm{B}$ than group $C$ at 5 to $45 \mathrm{~min}$ and 20 to $75 \mathrm{~min}$ respectively. Thereafter, at the end of observation period animals of group B and $\mathrm{C}$ showed no motor incoordination (Fig 3b).

\section{Physiological parameters:}

Heart rate: A significant $(\mathrm{P}<0.05)$ decrease in the heart rate was recorded in group $\mathrm{A}$ animals throughout the observation period starting from 30 min of spinal injection. In the animals of group B also, a significant $(\mathrm{P}<0.05)$ decrease in the heart rate from 10-60 min was recorded and continued to be lesser than the base line till the end of observation period. In group $\mathrm{C}$ animals no significant $(\mathrm{P}>0.05)$ change in heart rate was recorded throughout the observation period. Comparison among groups revealed that depression in heart rate was most significant $(\mathrm{P}<0.05)$ in group $\mathrm{B}$ than other groups (Fig 4a).

Respiratory rate: Group A animals, showed a significant $(\mathrm{P}<0.05)$ decrease in the respiration rate for 5 to $10 \mathrm{~min}$ post injection and $2 \mathrm{hrs}$ after the injection. It remained near the base value till the end in group B except for a transient rise in the begining, animals of group $\mathrm{C}$ showed an initial decrease in respiratory rate from 5 to $15 \mathrm{~min}$ post-injection, which was significant $(\mathrm{P}<0.05)$ at $15 \mathrm{~min}$. Comparison among different groups revealed that no significant $(\mathrm{P}$ $>0.05)$ difference in the respiration rate at any time interval was recorded among different groups (Fig 4b).

Rectal temperature: Group A and Group B however, showed a significant $(\mathrm{P}<0.05)$ decrease in rectal temperature throughout the period of observation. The rectal temperature was significantly lower in group B than other groups. Group C animals, showed a non-significant $(\mathrm{P}>0.05)$ change in rectal temperature (Fig 4c).

\section{Discussion}

The early onset of analgesia, complete analgesia of most of the regions and prolonged duration of analgesia in group A and B as compared to the group C which did not attain complete analgesia of any region was probably due to the fact that $\alpha_{-2}$-adrenoceptor 

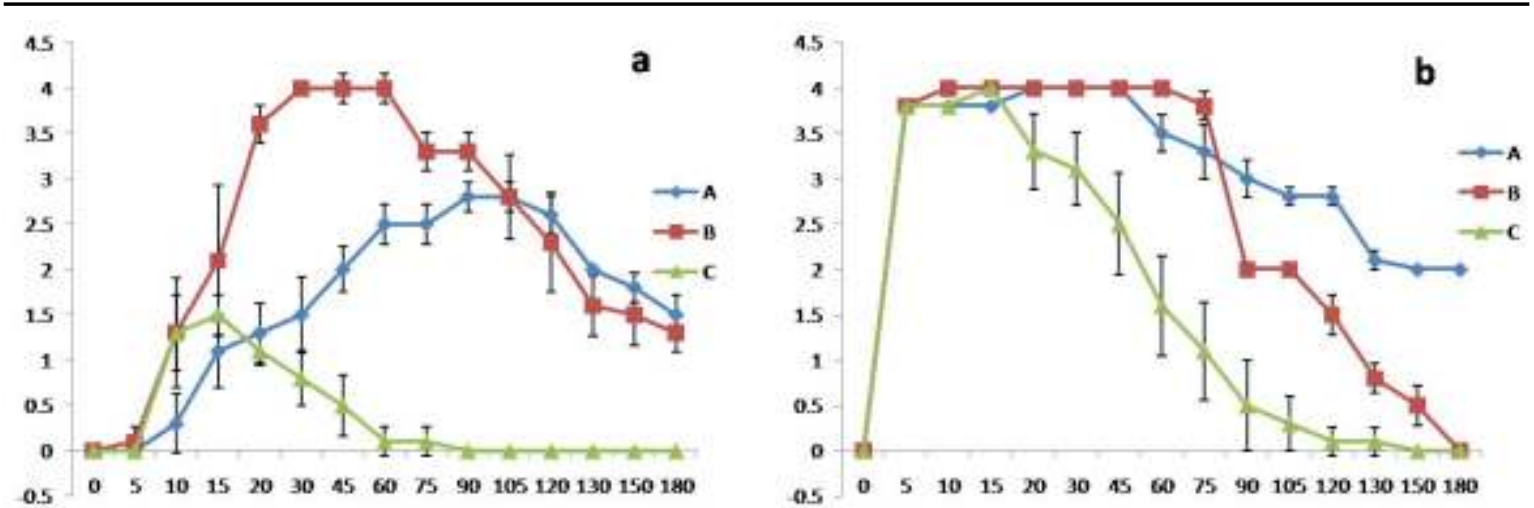

Figure-3. Scores of (a) Sedation recorded (b) Motor incoordination, after spinal admistration of the drugs ( ; bupivacaine $\mathrm{B}$; bupivacaine+ketamine)
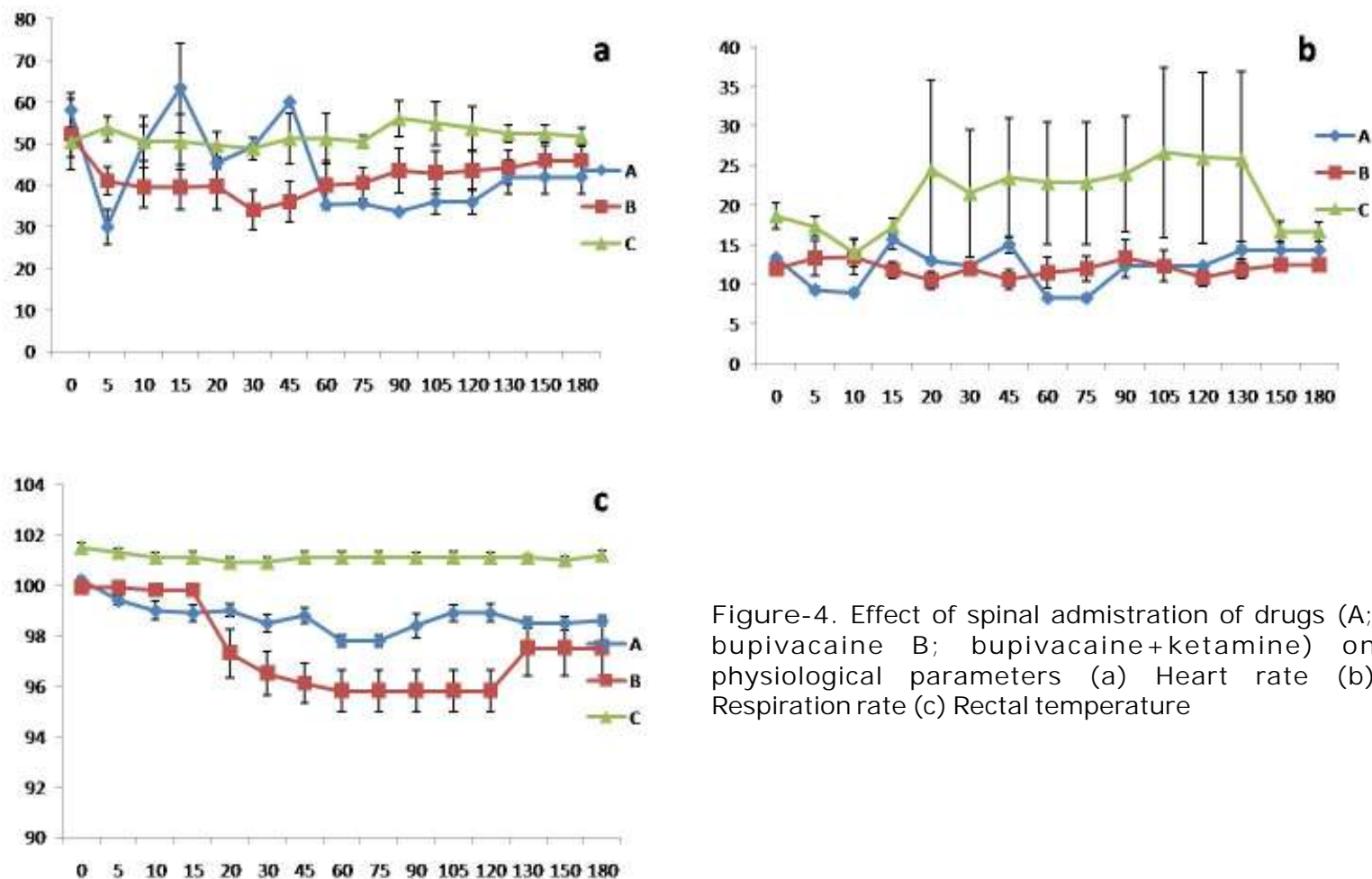

agonists provide a local depot of the drug and are released slowly over a longer period of time. The primary site of antinociceptive action of $\alpha_{2}$-agonists after intrathecal administration is at $\alpha_{2}$-adrenergic receptors in the substantia gelatinosa of the dorsal horn of spinal cord [10] where they inhibit the release of substance $P$, which is involved in pain sensation. Onset of analgesia in group B, (xylazine + ketamine), is in accordance with the similar findings of [11] which suggested a stronger synergistic action of the

combination. Buprenorphine is a partial mu opioid and a weak kappa agonist. It has a high affinity for the receptors, with slow dissociation resulting in a long duration of action. At higher doses, its agonist effects plateu and it begins to behave more like an antagonist, limiting the maximal analgesic effects. This is called ceiling effect [8]. A slow onset of opioids was also reported [12]. Action of the drugs at separate anatomic sites may lead to show distinct synergistic effects of the drugs. Ketamine is a potent non-competitive 
antagonist of NMDA receptors, which are involved in the transmission and modulation of nociceptive information at the spinal cord level [13].

Ketamine and bupivacaine, by acting at two different sites might have had synergistic additive action in the present study and caused a quick onset, higher depth of analgesia and prolonged duration of analgesia.

Group B produced extreme degree of sedation as compared to other groups. Salivation was also noticed in most of the animals. This indicates that the drug after absorption from the subarachnoid space was distributed to the brain. The sedative effect of $\alpha_{2^{-}}$ agonists is associated with the activation of central $\alpha_{2}$ adrenoceptors, which causes decrease in the release and turnover of norepinephrine in the CNS. The sedative effects of epidural administration of xylazine are due to the systemic effect of the drug after absorption through longitudinal epidural veins and possibly the lymphatics [14]. Comparable degree of sedation was reported following spinal injection of xylazine alone or ketamine and xylazine combination in cattle [15] Frequent urination was noticed in most of the animals after administration of $\alpha_{2}$-agonist alone and in combination with ketamine. This might be due to inhibition of production and release of $\mathrm{ADH}$, due to paralysis of sympathetic nerves to the sphincter of the bladder could also have been a cause of micturition as reported by. Diuresis was also observed with medetomidine and xylazine in dogs [15]. Increased urinary output following xylazine [16]. Group A (Ketamine + bupivacaine) animals remained less sedated throughout the period of observation. The finding was coherent with the observations of Kinjavdekar, 1998 [17] and Locatelli et al., 1997 [18], following spinal administration of ketamine. group C (ketamine + buprenorphine) animals, only a mild degree of sedation with slight ptosis of eye lids was observed. The mild sedation was also accompanied with marked euphoria in the animals of group $\mathrm{C}$ throughout the period of observation. This euphoria was manifested as paddling of limbs, pressing of head against wall and hitting the head continuously to ground wall. Similar finding was reported in cats with i.m buprenorphine [19]. Opioid induced sedation was reported not to increase further when combined with ketamine, this might have explained comparatively lesser duration of sedation in group C. Further buprenorphine is lipophillic and its delayed effect is usually related to slow receptor binding which occurs with partial agonists.

In group A animals, an extreme incoordination persisted till the end of observation period. The indiscriminate blockade of sensory and motor fibers was observed following spinal injection of lignocaine. Similar findings were reported by Fressei et al. 2008 [20]. Higher scores of motor incoordination in group B (ketamine and xylazine) might be due to additive or possibly synergistic effect of xylazine with ketamine at the spinal level, leading to more intense spinal effect. Similar findings were reported by Pathak et al, 2009 [21] in goats and Singh et al. 2010 [11] in cattle. Animal of group $\mathrm{C}$ showed least incoordination. This finding could be well explained probably by the findings of Amarpal et al. 2003 [22], who have recorded an antagonistic interaction between epidural pethidine and ketamine in dogs. Recovery from the effects of different drugs was in the order as group C followed by group A followed by group B. Reduction in HR after epidural/spinal administration of bupivacaine has been reported in dogs [23], goats [24], and buffalo [25], the decrease in HR was significantly more in group B than other groups.

No appreciable change in heart rate was observed after spinal administration of buprenorphine in combination with ketamine. Buprenorphine being more lipophillic gets less absorbed into vascular/ lymphatic circulation from subarachnoid space [26]. Buprenorphine i.v. or i.m did not produce alterations in the cardiovascular parameters that could provide any significant clinical effects in dogs [27]. Buprenorphine was shown to have a ceiling effect for respiration rate but not analgesia [28].

Group A and B also showed a decrease in the respiration rate which was significant in group $\mathrm{A}$ and non significant in group B but the animals of group C showed an increase in the respiration rate. The results suggested that ketamine in group A failed to counteract the respiratory depressant action of bupivacaine. It could be due to the fact that bupivacaine induced the decrease in RR through the blockade of nerves innervating the muscles of respiration as suggested by Rayees et al, 2011[29]. On the other hand, in group B the respiratory depression produced by xylazine could be well balanced by predominant stimulatory effect of ketamine which balanced the CNS depressant effect $\alpha$ -2-agonists [30]. The elevated RR in animals of group $\mathrm{C}$ might have been mainly due to the stimulatory effect of ketamine on the respiratory centres. Buprenorphine has been reported to have a "ceiling effect" on cardiopulmonary depression $[8,31]$.

In group A and B, Rectal temperature reduced significantly for longer duration but showed nonsignificant increase in group $\mathrm{C}$. The decrease in RT might be due to generalized sedation, decrease in 
metabolic rate, muscle relaxation and CNS depression produced by sedative and analgesic agents. Alpha-2 agonists have been reported to induce prolonged depression of thermoregulation [32] and depress hypothalamic nor-adrenergic $\alpha_{2}$-receptors to cause hypothermia [33]. Decrease in RT by $\alpha_{2}$-agonists related to central $\alpha_{2}$-adrenergic mechanisms [34] but probably also related to other depressing CNS mechanisms, because hypothermia could not be prevented by prior administration of Yohimbine [35]. Hypothermia with epidural bupivacaine was concurrent with the findings of Rayees et al, 2011 [29]. The non significant increase of rectal temperature in group C might have been due to the less sympatholytic activity of buprenorphine due to more tightly bounded to receptors and hyperalgesia associated with opioid which is neutralized to some extent by ketamine.

\section{Conclusion}

It can thus be concluded from the above study that both the combinations i.e. group A and B are effective for analgesia of observed dermatomes for prolonged periods of time without any observed side effects in buffalo calves. Spinal bupivacaine and xylazine when given with ketamine combinations have similar analgesic potency on spinal administration in buffaloes. At some observation points it was refelected that xylazine as compared to bupivacaine showed more synergistic effects as it was seen with respiration, motor incordination, sedation, analgesia. Whereas buprenorphine and ketamine combination in the said dose is a poor analgesic agent when used spinally in buffalo calves.

\section{Author's contribution}

All authors contributed equally. All authors read and approved the final manuscript.

\section{Acknowledgements}

We are pleased to acknowledge the Director, Indian Veterinary Research Institute for providing the funds for successfully carrying out this study under the institute project.

\section{Competing interests}

Authors declare that they have no competing interest.

\section{References}

1. Lumb W.V. and Jones E.W. (1984). Spinal anesthesia. In: Veterinary Anaesthesia. Lea and Febiger, Phliadelphia., 9393-412.

2. Pathak R. (1999). Post-traumatic pain and stress management in goats: Preemptive analgesia with epidural bupivacine hydrochloride and xylazineketamine. M.V.Sc. thesis submitted in Vety. Surg. IVRI, Izatnagar.

3. Pathak R., Amasrpal, Kingavdekar P., Pratap K. and Singh G.R. (2002). Reduction of pain by neuroxial blocade with bupivacaine. Indian J. Anim. Sci., 72(7): 535-538.

4. Taleska G., Trajkovska T., Kokareva A., Popovska A., Naumoska M., Gavrilovska A., DzhambazovskaTrajkovska V., Toleska M., DimovMacedonian A., (2010). Preemptive Epidural Analgesia with Bupivacaine and Sufentanyl and the Effects of Epiduraly Added Epinephrine for Thoracic Surgery. J. of Med. Sci., 3(1): 46-53.

5. Kinjavdekar P., Singh G.R., Amarpal., Aithal HP., Pawde AM., (2000). Physiologic and biochemical effects of subarachnoidally administered xylazine and medetomidine in goats. Small Rumin Res., 38: 217228.

6. Pathak R., Kushwaha R.B., Kumar S. (2009). Clinicophysiological effects of intraspinal and intramuscular xylazine - ketamine in uremic buffalo calves. The Indian J. of Vet. Res., 18:1.

7. Caron, J.P. and LeBanc, P.H. (1989). Caudal epidural analgesia in cattle using xylazine. Can J. Vet. Res., 53: 486-489.

8. Sporer K.A. (2004). Buprenorphine : a primer for emergency physicians. Ann. Emerg. Med., 43(5): 580584.

9. Trujillo K.A. (2000). Are NMDA receptors involved in opiate induced neural behaviour plasticity? A review of preclinical studies psychophacology (Beri), 151(2-3): 121-41.

10. Yaksh T.L. (1985). Pharmacology of spinal adrenergic systems which modulate spinal nociceptic proceedings. Pharmacol. Biochem. Behav., 22: 845858.

11. Singh V., Amarpal., Kinjavdekar P., Aithal H P., Pawde A M., (2010). Evaluation of ketamine and bupivacaine with xylazine for epidural analgesia in buffalo calves. Indian J. of Ani. Sci., 80: 9.

12. Hindle A. (2008). Intrathecal opioids in the management of acute postoperative pain. Contin. Educ. Anaesth. Crit. Care Pain., 8 (3): 81-85.

13. Chizh BA. (2007). Low dose ketamine: a therapeutic and research tool to explore N-methyl-D-aspartate (NMDA) receptor-mediated plasticity in pain pathways., 21(3): 259-71.

14. Lee Danghee, Bae-Chunsik (2001). Effect of xylazine in cattle under rope restrained conditions. J. of Vet. Clinics, 18(3): 189-194.

15. Md. Hasanuzzaman T. and Yoshiaki H. (2009). Diuretic effects of medetomidine compared with xylazine in healthy dogs. Can J Vet Res, 73(3): 224-236.

16. Ozba B., Ozaydin I., Kilic E., Atalan G. and Baran V. (2003). Xylazine and zolezepam-Tiletamine 
anaesthesia in calves for uneblical operation. Indian Vet. J., 80: 46-48.

17. Kinjavdekar P. (1998). Spinal analgesia with alpha-2 agonists and their combinations with ketamine and lignocaine in goats. Ph.D. thesis submitted in Vet. Surg. IVRI, Izatnagar.

18. Locatelli B. G., Frawley G., Spotti A., Ingelmo P., Kaplanian S., Sonzogni V., Monia L., (2008). Analgesic effectiveness of caudal levobupivacaine and ketamine J. Anaesth. 100 (5): 701-706.

19. Robertson S.A., Taylor P.M., Lascelles B.D., Dixon M.J. (2003). Changes in thermal threshold response in eight cats after administration of buprenorphine, butorphenol and morphine. Vet. Rec., 153(15): 462465.

20. Freise H., Meissner A., Lauer S., Ellger B., Radke R., Bruewer M., Brodner G., Van Aken H.K., Sielenkämper A.W., Fischer L.G. (2008). Thoracic epidural analgesia with low concentration of bupivacaine induces thoracic and lumbar sympathetic block: a randomized, double-blind clinical trial Anesthesiol., 109(6): 1107-12.

21. Pathak R., Kushwaha R.B., Kumar S. (2009). Clinicophysiological effects of intraspinal and intramuscular xylazine - ketamine in uremic buffalo calves. The Indian J. of Vet. Res., 18 (1): 42-45.

22. Amarpal, Aithal H.P., Kinjavdekar P., Singh G.R. (2003). Interaction between epidurally administered ketamine and pethidine in dogs. J. Vet. Med. A Physiol. Pathol. Clin. Med. 50(5): 254-258.

23. Luna S.P., Cassu R.N., Castro G.B., Teixerira, Neto F.J., Silva Juniiior J.R., Lopes M.D. (2004). Effects of four anaesthetc protocols on the neurological and cardiorespiratory variables of puppies born by caesarean section. Vet. Rec. 154(13): 387-389.

24. Adetunji A., Ajadi R.A., Opia R.E. (2002). A comparison of epidural anaesthesia with xylazine, bupivacaine and bupivacaine/xylazine mixture in west aprican dwarf goats. Israel J. Vet. Med., 57(2): 76-81.

25. Hussain S.S. and Amresh K. (1988). Bupivacaine HCI for epidural anaesthesia in buffalo calves. Ind. $J$.
Vet. Surg., 9: 2-17.

26. Negus S.S., Bidlack J.M., Medlo N.K., Furness M.., Rice K.C., Brandt M.T. (2002). Delta opioid antagonist effects of buprenorphine is rhesus monkeys. Behav. Pharmacol. 13(7): 557-570.

27. Souza A.P., de Rezende M.L., de Nunes N., Nishimori C.T. et al. (2004). Buprenorphine cardiovascular and intracranial alterations in dogs anaesthetized with desfluorare. Ciencia Rural, 34(3): 815-820.

28. Daha A., Yassen A., Romberg R., Sarton E., Teppema L., Olofsen E. and Danhof M.. (2006). Buprenorphine induces ceiling in respiratory depression but not in analgesia. Br. J. Anaesth. 96(5): 627-632.

29. Rayees A., Shukla B.P., Jain R. (2011). Clinicophysiological changes following epidural analgesia by bupivacaine, ropivacaine or ropivacaine-xylazine combination in goats Indian J.of Vet. Surge., 32(1): 57-58

30. Singh P., Pratap K., Kinjavdekar P., Aithal H. P., Singh G.R., Pathak R. (2006). Xylazine, Ketamine and their Combination for Lumbar Epidural Analgesia in Water Buffalo Calves (Bubalus bubalis). J. Vet. Med. A Physiol. Pathol. Clin. Med., 53 (8): 423-31.

31. Umbricht A., Herestis M.A., Cone E.T., Preston K.L. (2004). Effects of high dose intravenous buprenorphine in experienced opioid abugers. J. Clin. Psychopharmacol., 24(5): 479-487.

32. Ponder S.W. and Clarke W.G. (1980). Prolonged depression of thermoregulation after xylazine administration to cats. J. Vet. Pharmacol. Ther., 3: 203-207.

33. MacDonald E.J., Cavan K.R. and Smith T.K. (1988). Effect of acute oral doses of T-2 toxin on tissue concentrations of biogenic amines in the rat. J. Anim. Sci., 66: 434-441.

34. Livingston A., Low J. and Morris B. (1984). Effects of clonidine and xylazine on body temperature in the rat. Br. J. Pharmacol., 81: 189-195.

35. Virtanen R., (1986). Pharmacology of detomidine and other a2- adrenoceptors agonists in the brain. Acta. Vet. Scand., 82: 35 46 . 